EESTI NSV TEADUSTE AKADEEMIA TOIMETISED, XV KÖIDE

FUUSIKA-MATEMAATIKA- JA TEHNIKATEADUSTE SEERIA. 1966, NR. 2

ИЗВЕСТИЯ АКАДЕМИИ НАУК ЭСТОНСКОИ ССР. ТОМ ХV

СЕРИЯ ФИЗИКО-МАТЕМАТИЧЕСКИХ И ТЕХНИЧЕСКИХ НАУК. 1966, № 2

\author{
А. ЛООГ, К. МЕНС, К. МЮЮРНСЕПП
}

\title{
О ГРАНИЦЕ ЛОНТОВАСКОЙ И ПИРИТАСКОЙ СВИТ НИЖНЕГО КЕМБРИЯ ПРИБАЛТИКИ
}

Среди древнепалеозойских отложений Эстонии до настоящего времени остаются стратиграфически слабо изученными кембрийские, что объясняется их плохой фаунистической охарактеризованностью.

В настоящей статье рассматривается один вопрос стратиграфии этих отложений, а именно - граница между лонтоваской («синие глины») и пиритаской (эофитоновые слои) свитами.

В более ранних раб̆отах $[1-6]$ указывалось, что резкая литологическая граница между лонтоваской и пиритаской свитами отсутствует и ее проводили по подошве пачки, состоящей из чередуюшихся слоев алевролитов и глин. При. этом за характерную фауну для верхней части лонтоваской свиты принимали Platyșolenites antiquissimus Eichw., P. Lontowa Öpik, Lingulella sp., Pleurotomaria (?) kunda Öpik, Hyolithus (Orthotheca)mickwitzi Öpik и Volborthella tenuis Fr. Schmidt [4,5], а для нижней части пиритаской свиты (люкатиская пачка) - Volborthella.tenuis Fr. Schmidt, Schmidtiellus mickwitzi (Fr. Schmidt), Mickwitzia monilifera Linn. и Platysolenites antiquissimus Eichw.

Таким образом, граница по существу проводилась условно. Т. Давыдова [7] пошліа г этом отношении еще дальше и предложила рассматривать лікатискую пачку и лонтоваскую свиту как одно целое.

Собранный авторами фактический материал позволяет однозначно провести границу между отложениями лонтоваской и пиритаской свит.

Ниже по данным 24 скважин и двух обнажений дается краткая характеристика лонтоваской свиты -и люкатиской пачки и более подробно рассматривается характер гра́ницы между ними (рис. 1).

Отложения лонтоваской свиты имеют на территории Эстонин почтй повсеместное распространение, за исключением южной части республики, где они отсутствуют на Мынистеском и Отепяском поднятиях. Максимальную мощность лонтоваская свита имеет в северо-восточной части республики $(80$ м) ; в западном и южном направлениях мощность ее уменьшается до 32 м (скв. Пярну 32,8 м, скв. Петсери 31,7 м). В нижней части свиты алевритовые и алевритистые глины переслаиваются с кварцевыми и глауконито-кварцевыми песчаниками и алевролитами с преобладанием первых. Верхняя часть разреза состоит из глин и алевритистых глин. Глины свиты гидрослюдистого состава. В состав алевритовой фракции глин входят: кварц (преобладает), полевые шпаты, глауконит и слюды (мусковит и биотит). Количество алевритовой фракции в глинах в верхней части разреза не превышает 25\% (кроме самой западной части территории). При этом наблюдается закономерное уменьшение алевритовой фракции кверху. Окраска глинистых пород в нижней и са- 


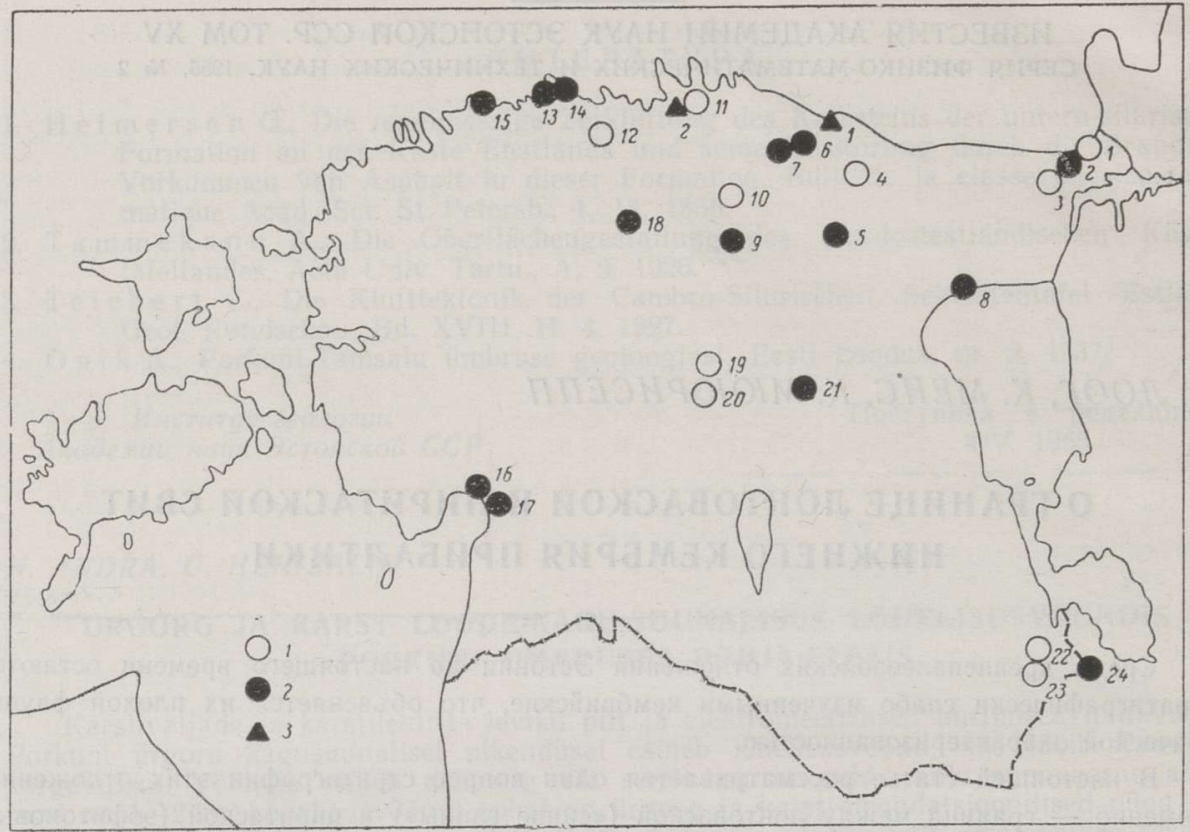

Рис. 1. Расположение скважин и обнажений, вскрывших границу лонтоваской свиты и люкатиской пачки.

Условные обозначения: 1 - скважина; 2 - скважина, в которой изучено распределение окаменелостей; 3 - обнажение.

С к в а жи ны: 1 - Утрия; 2 - Синимяэ; 3 - Вийвиконна; 4 - Ульясте; 5 - Виру-Роэла 6 - Эссу; 7 - Кестла; 8 - Раннапунгерья; 9 - Эллавере; 10 - Тапа; 11 - Корьюзе; 12 - Арукюла; 13 - Виймси-5; 14 - Виймси-8; 15 - Мурасте; 16 - Пярну I; 17 - Пярну II 18 - Арду; 19 - Эйамаа; 20 - Выхма; 21 - Паламузе; 22 - Вяймела; 23 - Выру; 24 Петсери. Обнажения: 1 - Кунда; 2 - Кольгакюла.

мой верхней (до 4 м) частях зеленовато-серая. В средней части разреза они пестро-цветные; чередуются глины зеленовато-серые, фиолетовые и красновато-коричневые. Текстура глин горизонтально-слоистая - тонкоплитчатая, мощность отдельных плиток обычно $1-2$, реже $5-10$ мм. По плоскостям наслоения изобилуют разной формы и величины пиритизированные ходы илоедов. Иногда эти ходы заполнены алевритовым материалом. Встречаются также отдельные мелкие кристаллы и конкреции пирита.

В двух пунктах (карьер Кольгакюла и скв. Мурасте) в верхах лонтоваской свиты среди глин наблюдаются линзы алевролита. В карьере Кольгакюла пачка глин с линзами алевролита имеет мощность 60 см; содержащиеся в ней линзы алевролита имеют мощность обычно $1-2 \mathrm{~cm}$ и длину до 20 см. Алевролиты этих линз кварцевые и обладают светлосерой окраской с розоватым оттенком. Кроме кварца, в них в виде примеси присутствуют глауконит, мусковит и биотит. Они сцементированы иленочным фосфатным и базальным или поровым глинистым цементом. В скважине Мурасте мощность такой пачки равна 1 м.

При наличии в разрезе люкатиской пачки в верхней части лонтоваской свиты отсутствуют следы выветривания: глинистые частицы пород лонтоваской свиты по всему разрезу представлены гидрослюдами; отношение $\mathrm{Fe}_{2} \mathrm{O}_{3}$ : $\mathrm{FeO}$ более или менее постоянное, равное $1,5-1,6$. Там, где отложения люкатиской пачки отсутствуют, а именно в юго-восточной части Әстонии, верхи лонтоваской свиты несут следы выветривания: цвет глин здесь желтовато-коричневый (табачный), а в самых верхних слоях 
почти белый; по составу эти глины каолинитовые; отношение $\mathrm{Fe}_{2} \mathrm{O}_{3}$ : $\mathrm{FeO}$ в них доходит до 16 .

Разрез отложений лонтоваской свиты завершается неровно-волнистой поверхностью, что хорошо видно в карьерах Кунда и Кольгакюла. По скважинам неровности этой поверхности (из-за небольшого диаметра керна) не обнаруживаются. На этой неровной поверхности залегает местами базальный конгломерат люкатиской пачкй, который обнаружен в карьерах Кунда и Қольгакюла, а также в скважинах Мурасте и ВируРоэла*.

В карьере Кунда конгломерат прослеживается по всей обнаженной части стенок общим протяжением более 100 м; залегание его прерывистое - местами до нескольких метров он отсутствует. Мощность конгломератовых тел колеблется от долей сантиметра (отдельные крошечные гальки) до $10 \mathrm{~cm}$ (рис. $2 a$ и 3 ).

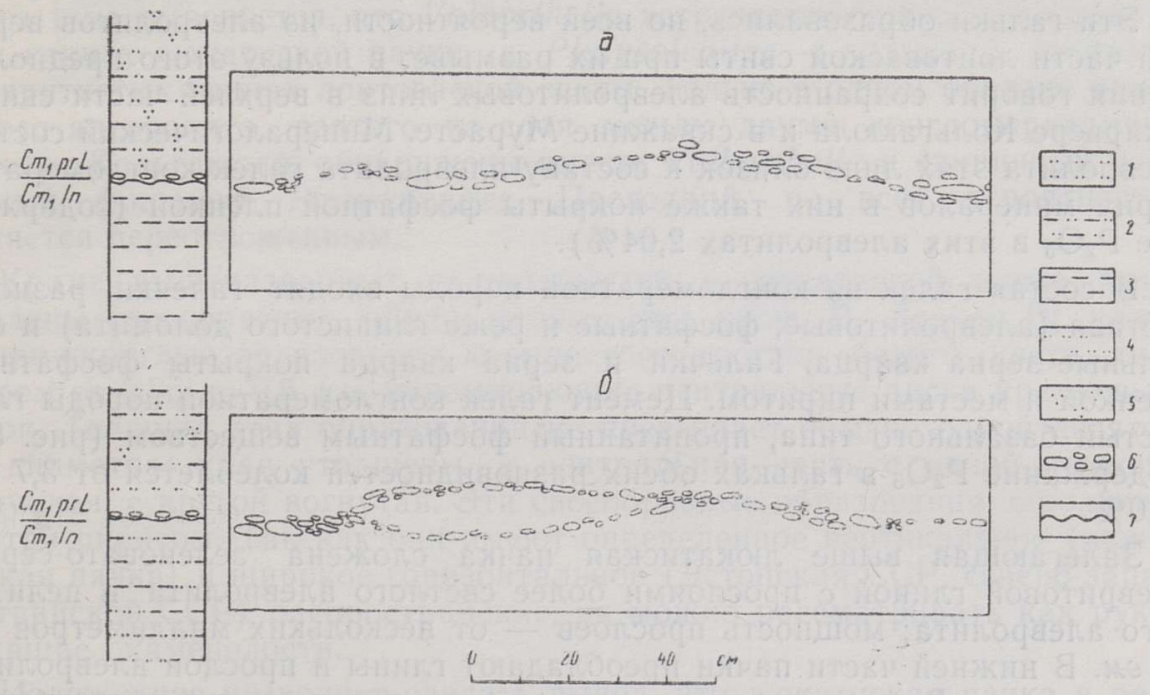

Рис. 2. Схематический геологический разрез карьеров Кунда $(a)$ и Кольгакюла (б): 1 - алевролиты; 2 - алевритовые глины; 3 - глины; 4 - линзы алевролита; 5 - гнезда глауконита и кварца; 6 - гальки; 7 - поверхность размыва.

В карьере Қольгакюла на неровной поверхности глин с линзами алевритов лонтоваской свиты залегают местами два слоя конгломерата (мощность $1-3$ см), отделенные друг от друга слоем алевритовой глины мощностью до 10 см (рис. 2б). Местами, подобно карьеру Кунда, конгломератовый слой в разрезе отсутствует либо представлен одним слоем мощностью до $6 \mathrm{cM}$.

Скважиной Мурасте в интервале 51,60-51,40 м в основании люкатиской пачки вскрыты алевролитовые гальки с фосфатным цементом, размещенные в алевритовой глине в виде нескольких параллельно рас- положенных прослоев.

В скважине Виру-Роэла на поверхности глин лонтоваской свиты (глубина 189,0 м) встречены маленькие алевролитовые гальки с фосфатным или глинистым цементом.

* Гальки в верхней части синих глин были отмечены также А. Эпиком $[3,4]$. 
Конгломерат в названных местах состоит из горизонтально расположенных плоских светлых и темных галек алевролита и галек сильно сцементированной конгломератной породы; цементом конгломерата служит зеленовато-серая алевритовая глина. Размеры галек колеблются в больших пределах. Большей частью диаметр их не превышает одного сантиметра, а толщина 2-4 мм. Встречаются гальки диаметром до 20 cm нри толщине до 7 см (рис. 4) .

Гальки алевролитового состава сложены зернами кварца разной стегени окатанности, в некоторых случаях с примесью слюд (мусковит и биотит), глауконита, полевых шпатов и пирита. Все эти зерна покрыты тонкой фосфатной пленкой и сцементированы глинистым цементом, пропитанным фосфатными соединениями -и местами окислами железа. В некоторых алевролитовых гальках наблюдается горизонтально-слоистая текстура: листочки слюд ориентированы и наблюдается слойчатое распределение глауконита и зерен кварца по крупности.

Эти гальки образовались, по всей вероятности, из алевролитов верхней части лонтоваской свиты при их размыве; в пользу этого предположения говорит сохранность алевролитовых линз в верхней части свиты в карьере Кольгакюла и в скважине Мурасте. Минералогический состав алевролита этих линз близок к составу алевролита галек конгломерата. Зерна минералов в них также покрыты фосфатной пленкой (содержание $\mathrm{P}_{2} \mathrm{O}_{5}$ в этих алевролитах $2,04 \%$ ).

В состав галек из конгломератной породы входят галечки разного состава (алевролитовые, фосфатные и реже глинистого доломита) и отдельные зерна кварца. Галечки и зерна кварца покрыты фосфатной пленкой и местами пиритом. Цемент галек конгломератной породы глинистый базального типа, пропитанный фосфатным веществом (рис. 5). Содержание $\mathrm{P}_{2} \mathrm{O}_{5}$ в гальках обеих разновидностей колеблется от 3,7 до $12,0 \%$.

Залегающая выше люкатиская пачка сложена зеленовато-серой алевритовой глиной с прослоями более светлого алевролита и пелитового алевролита; мощность прослоев - от нескольких миллиметров до 20 cм. В нижней части пачки преобладают глины и прослои алевролита здесь тоньше. Верхняя часть разреза состоит почти в равных соотношениях из глинистых и алевритовых прослоев. В западном направлении породы становятся крупнозернистее; в нижней части они представлены здесь пелитовыми, а в верхней - песчаными алевролитами.

Отложения люкатиской пачки распространены в Эстонии менее широко, чем нижележащая лонтоваская свита. Кроме Мынистеского и Отепяского поднятия они отсутствуют и в Юго-Восточной Эстонии. Обнажаются они в обрывах глинта в многочисленных пунктах от г: Таллин до г. Нарвы. Здесь люкатиская пачка имеет и максимальную мощность (до 15 м). В южном и западном направлениях мощность пачек постепенно уменьшается (в скв. Арду - 4,9 $л$, в скв. Пярну - 2,4- $\mu$, в скв. Паламузе - 5,8 и и т. д.) до полного выклинивания на юге Эстонии (скважины Выру, Вяймела, Петсери и др.).

Глины люкатиской пачки имеют гидрослюдистый состав- Их алевритовая фракцня представлена кварцем с примесью слюд либо кварцем с глауконитом. Кроме рассеянных зерен кварца и плауконита алевритовой и песчаной фракций встречаются и скопления их в виде небольших гнезд, что представляет собой характерную особенность алевритовых глин люкатиской пачки. Это позволяет хорошо отличать в разрезе люкатиские глины от лонтоваских. Алевролиты кварцевые либо глауконитокварцевые от слабо до сильно сцементированных. Слабо сцементирован- 
ные разновидности имеют глинистый цемент базального или контактового типа, а сильносцементированные - доломитовый пойкилокластический цемент. В глинах и алевролитах встречаются кристаллы и конкреции пирита. Текстура пород люкатиской пачки - горизонтально-слоистая, реже линзовидная или волнистая. На плоскостях наслоения встречаются асимметричные знаки ряби, трещины усыхания, следы капель дождя и ходы илоедов. Последние в нижней частй пачки сплюснуты и пиритизированы, а в верхней - округлые и заполнены алевритовым материалом.

Кроме литологических различий, отложения лонтоваской свиты и люкатиской пачки отличаются друг от друга также фаунистически, особенно по наиболее распространенным окаменелостям: Platysolenites и Volborthella*.

По материалам 14 скважин и обнажений Кунда и Кольгакюла (пробы выбирались вблизи границы через $0,5 \mathrm{~m}$, а в остальной части разреза через 1 м) выясняется, что Volborthella встречается только в алевритовых глинах люкатиской пачки, а Platysolenites - только в глинах и алевритистых глинах лонтоваской свиты. Только в одном образце пелитового алевролита, взятого из слоя между двумя конгломератами в карьере Кольгакюла, обнаружены вместе Volborthella и единичный окатапный фрагмент Platysolenites. Последний, по всей вероятности, является переотложенным.

Кроме вышеназванных окаменелостей в люкатиской пачке нами найдены своеобразные, обнаруженные уже проф. В. Деекем [8], уплощенно-округлые образования кремнистого состава белого цвета, диаметром от 0,05 до 0,5 мм, напоминающие центральные диски кремневых губок. Толщина этих образований не превышает обычно одной десятой нх диаметра; края утолщены, а центральная часть с одной стороны выпуклая, с другой вогнутая. Эти своеобразные образования заполнены внутри пиритом. Так как они имеют определенное вертикальное (люкатиская пачка) и широкое горизонтальное (Әстонская ССР, северо-запад Латвийской ССР) распространение, их можно рассматривать как руководящие окаменелости.

Изложенное позволяет сделать вывод, что люкатиская пачка в рассматриваемом авторами объеме соответствует выделенной А. Эпиком $[3,5]$ зоне с Volborthella и границу между лонтоваской и. пиритаской свитамн сллдует проводить между зоной с Platysolenites и зоной c Volborthella. На этом уровне изменяется гранулометрический состав отложений и макролитологический облик самих пород, а местами граница маркируется и конгломератом,

\section{Л ИТЕРА Т У РА}

1. Mickwitz A., Archaikum, Kambrium, Silur, In: Baltische Landeskunde, Riga, 1911.

2. Rüger L., Paläogeographische Untersuchungen im baltischen Cambrium unter Berücksichtigung Schwedens, Zbl. Mineral., Geol. u Paläontol., Abt. B, 1923.

3. O pik A., Beitrag zur Stratigraphie und Fauna des estnischen Unter-Kambriums (Eophyton-Sandstein). Publications of the Geol. Instit. of Tartu, No. 3. Tartu, 1925.

4. Op ik A., Uber den estländischen blauen Ton, Sitzungsberichte der NaturforscherGesellschaft bei der Universität Tartu, XXXIII (1). Tartu, 1926.

* На необходимость ревизии объема вертикального распространения Volborthella обратил внимание Р. Мянниль [6]. В 1961 г. А. Мардла (рукописная работа) на основании изучения разрезов северо-восточной Әстонии установил, что Platysolenites встречается в лонтоваской свите, a Volborthella - в пиритаской. 
5. Öpik A., Cambrian (Lower Cambrian) of Estonia, In: XX Congr. Geol. Internat. El sistemo cambrico, su paleogeografia y el problema de su base, t. 1, p. 1. Mexico, 1956.

6. Мянни иль Р. М., Кембрийская система, Геология СССР, т. XXVIII, Эстонская CCP, M., 1960.

7. Д а в ы до в а Т. Н., Қ стратиграфии отложений между «синими глинами» и пакерортскими слоями северной части Советской Прибалтики, Изв. АН СССР. Сер. геол., № 8 (1964).

8. Hecker R., Uber Akademiker Fr. Schmidts Ansicht inbetreff der Natur der Platysoleniten und über die von Prof. W. Deecke erlangten Resultate beim Abschlämmen des blauen Tones von K̦unda, Ежегодник Палеонтол. об-ва, т. VII, 1928.

$\begin{array}{cc}\text { Институт геологии } & \text { Поступила в редакцию } \\ \text { Академии наук Эстонской ССP } & 2 / \mathrm{VI} 1965\end{array}$

\section{A. LOOG, K, MENS, K. MUURISEPP}

\section{BALTIKUMI ALAMKAMBRIUMI LONTOVA JA PIRITA KIHISTU PIIRIST}

Senini on lontova ja pirita kihistu vahelist piiri nii litoloogiliselt kui ka faunistiliselt nimetatud ebateravaks. Käesoleva uurimistööga on selgitatud täiesti selge piiri olemasolu nende kihistute vahel. See väljendub kohati põhikonglomeraadi esinemises piiril, kivimite erinevas litoloogilises koosseisus ning juhtkivististe (Platysolenites antiquissimus Eichw., Volborthella tenuis F. Schmidt) järsus vahetumises. A. Öpiku ${ }^{[3,5]}$ poolt eraldatud Volborthella-vöö vastab käesolevas töös käsitletava lükati kihistiku mahule. Seega langeb lontova ja lükati kihistu vaheline piir kokku Platysolenites- ja Volborthella-vöö vahelise piiriga.

\section{A. LOOG, K. MENS, K. MOURISEPP}

\section{ON THE BORDER OF THE LONTOVA AND PIRITA FORMATIONS IN THE BALTIC}

Up to the present time the border between the Lontova and Pirita formations was known to be lithologically and faunistically inconspicuous. According to the investigations oi the authors of the present paper, a very clear border is established between these formations. It is marked by a local distribution of a basal conglomerate on the border, by a distinct lithological composition and a change of the trace fossil (the Platysolenites antiquissimus Eichw. of Lontova formation is abruptly replaced by Volborthella tenuis F. Schmidt in the Pirita formation). The Volborthella-Zone distinguished by A. Opik $[3,5]$ corresponds to the Lükati member in the volume treated by the authors, and the border between the Lontova formation and Lükati member coincides with the boundary between the Platysolenites-zone and the Volborthella-zone. 


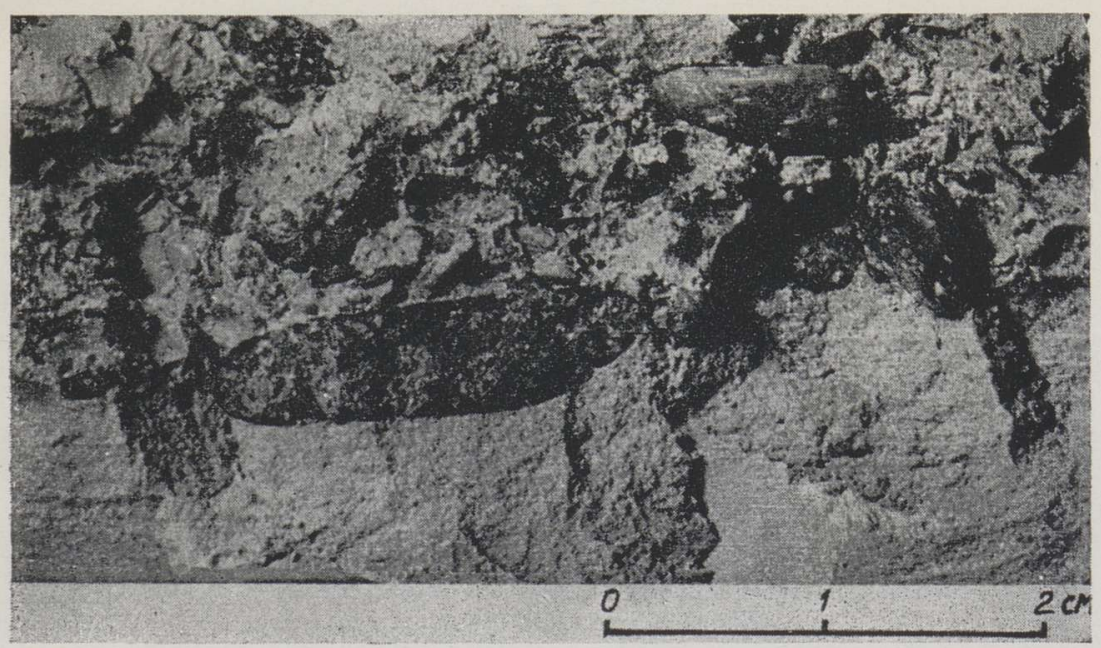

Рис. 3. Қонгломерат в карьере Кунда.

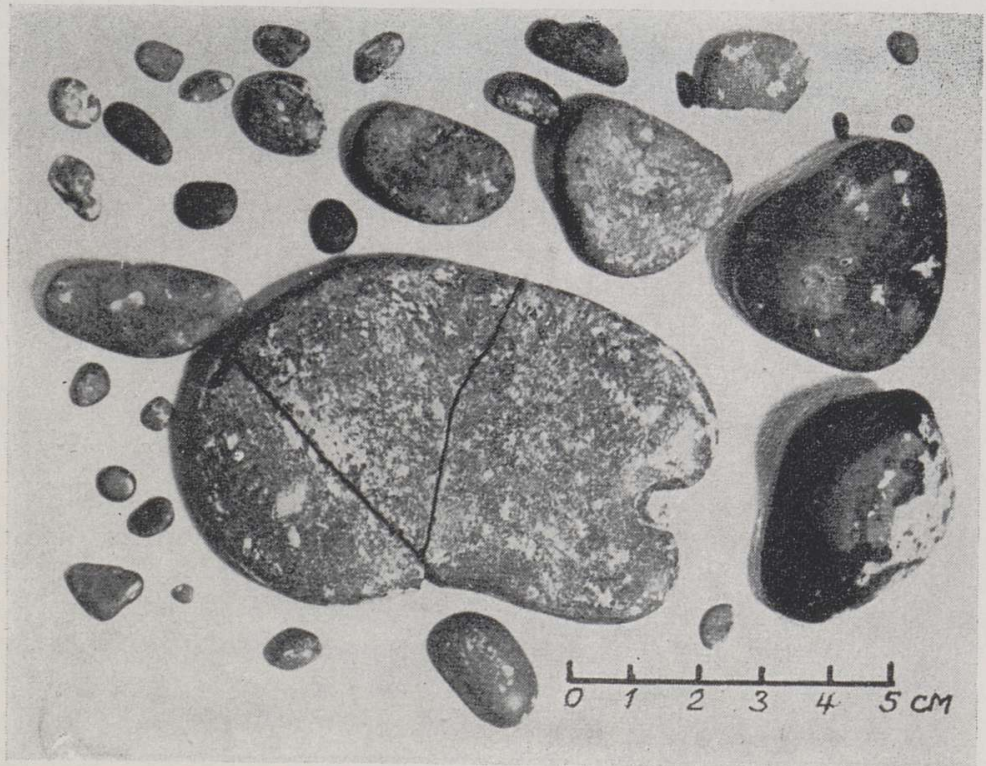

Рис. 4. Гальки конгломерата из карьера Кунца. 


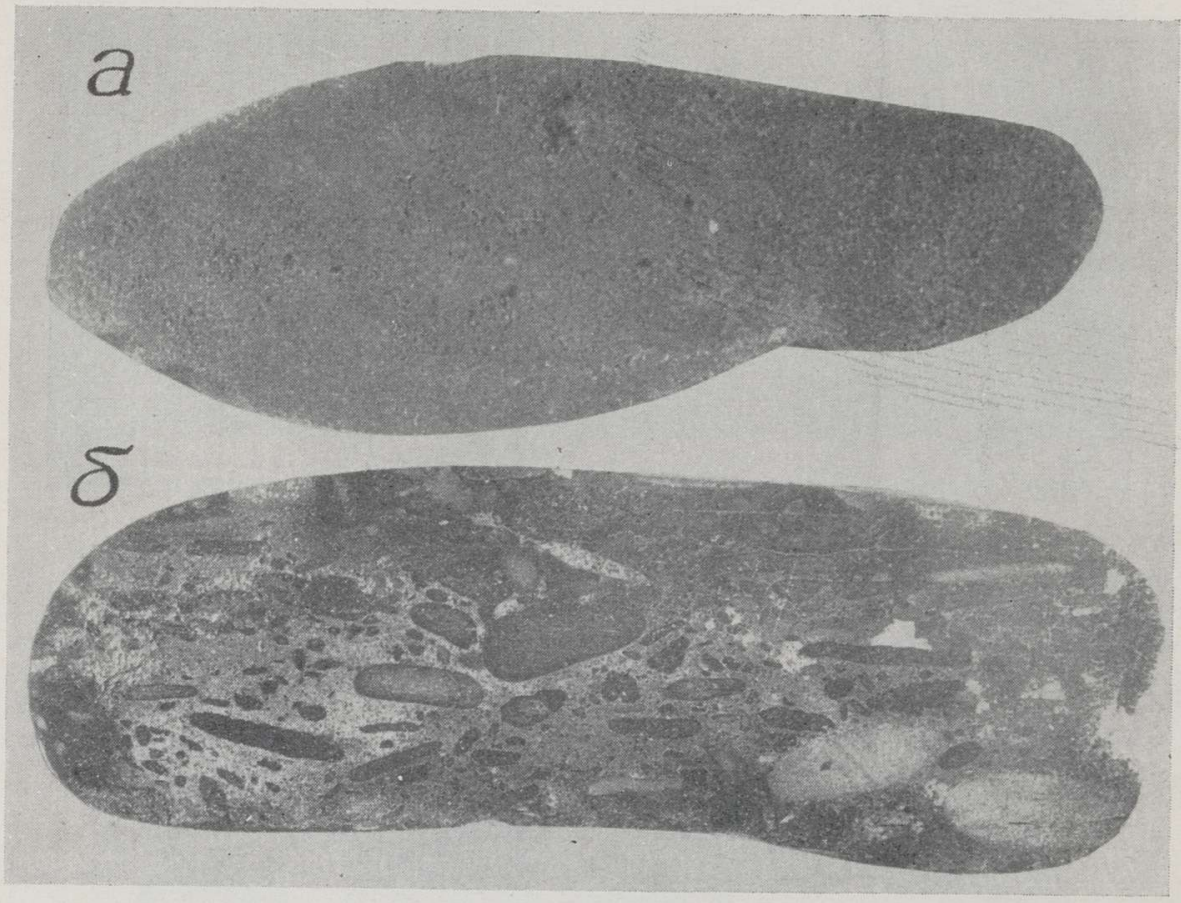

Рис. 5. Пришлифовки галек из алевролита $(a)$ и конгломератной породы (б). 1 X. 